\title{
Effect of Rhizobium Inoculants and Reproductive Growth Stages on Shoot Biomass and Yield of Soybean (Glycine max (L.) Merril)
}

\author{
S. Lamptey ${ }^{1}$, B. D. K. Ahiabor ${ }^{2}$, S. Yeboah ${ }^{3} \&$ D. Osei ${ }^{2}$ \\ ${ }^{1}$ Department of Agronomy, University for Development studies, Tamale, Ghana \\ ${ }^{2}$ CSIR -Savanna Agricultural Research Institute, Tamale, Ghana \\ ${ }^{3}$ CSIR-Crops Research Institute, Kumasi, Ghana
}

Correspondence: S. Lamptey, I Department of Agronomy, University for Development studies, Tamale, Ghana. Tel: 233-244-649-270. E-mail: naalamp2009@yahoo.com

\author{
Received: February 11, 2014 Accepted: March 10, 2014 Online Published: April 15, 2014 \\ doi:10.5539/jas.v6n5p44 URL: http://dx.doi.org/10.5539/jas.v6n5p44
}

\begin{abstract}
The experiment was conducted during the 2012 farming season in the agricultural experimental field of the University for Development Studies, Nyankpala in the Northern Region of Ghana. The objective of the study was to determine the influence of Rhizobium inoculants and growth stages on shoot dry matter and grain yield of soybean. Two levels of inoculation regimes (inoculation (+In) and uninoculation (-In)) were combined with four sampling developmental stages (vegetative stage, flowering stage, pod stage and physiological maturity stage). The experimental design was a 2 x 4 factorial laid out in a Randomized Complete Block Design with eight treatments at four replications. Plants inoculated with Rhizobium and harvested at flowering stage recorded significantly higher fresh and dry shoot matter of $74.2 \mathrm{~g}$ and $23.57 \mathrm{~g}$ per plant, respectively as compared to plants that were not inoculated and harvested at the physiological maturity stage. The latter recorded the lowest fresh and dry shoot weights of $45.2 \mathrm{~g}$ and $15.5 \mathrm{~g}$ per plant, respectively. Rhizobium inoculation significantly increased grain yield (1262 kg/ha) compared to the yield obtained in the uninoculated treatments $(1044 \mathrm{~kg} / \mathrm{ha})$. Grain yield positively correlated with plant height, plant stand, canopy spread, number and weight of nodules, number and weight of pods. From the results, it is recommended that soybean seeds should be inoculated with Rhizobium before planting in order to obtain higher grain yields. It is also recommended that for higher nodule numbers, which can be a good indication of higher $\mathrm{N}_{2}$ fixation if the nodules are effective, and higher shoot biomass which is required for effective green manuring, soybean should be harvested at full pod stage.
\end{abstract}

Keywords: inoculation regime, rhizobium, growth stages, soybean, grain yield

\section{Introduction}

Soybean (Glycine max (L.) Merrill) is an oil crop whose cultivation is gaining popularity in northern Ghana. Soybean grows well in warm and moist climates with an optimum temperature of $26.5^{\circ} \mathrm{C}$ to $30^{\circ} \mathrm{C}$. It grows on well-drained fertile loamy soils with a pH of 6.0 to 7.5. Soybean is rich in protein and it is used to fortify various foods in order to improve their nutritional quality (IITA, 1990). It is also important in the supply of high quality animal feed and green manure (Miller et al., 1997). It has been estimated that 1.6 million metric tons of soybean grains are needed annually to satisfy domestic and industrial needs (Mamman, 1990). However, production of soybean is challenged by poor crop establishment, inappropriate planting depth, use of unimproved seeds, low soil fertility and lack of effective nodulation (Lawson \& Quainoo, 2008). Annual soybean yields have increased nationwide over the last 15 years (USDA NASS, 2011). This increase has come from a combination of genetic improvements and the introduction of biotechnology and improved cultural practices. Selective breeding has also improved grain composition, increased pest tolerance and increased yield potential. The utilization of newer biotechnology techniques has also allowed soybean breeders to insert desired traits into soybean germplasm. While the yield potential of soybean is genetically determined, achieving full yield potential also requires an optimum environment. In general, aside from cultivar selection, manipulation of soybean planting date, seeding rate, row spacing and weed control; rhizobium inoculation is a major agronomic factor that can significantly influence the yield potential and economic returns of soybean. When soybean roots are infected by the appropriate native Rhizobium or through artificial inoculation with effective rhizobial strains, nodules are generally formed with regard to their potential for nitrogen fixation (Shu-Jie et al., 2007). The artificial inoculation is very cheap and 
it increases the efficiency of the plant to fix free elemental nitrogen $(\mathrm{N})$ from the atmosphere and also serves as insurance for getting good pulse crops. The legume has been characterized to be more responsive to the use of symbiotically fixed $\mathrm{N}$ source than the application of fertilizer $\mathrm{N}$ (Board \& Hall, 1983). It is therefore, recommended to artificially inoculate the seeds with an appropriate strain of Rhizobium before sowing. The greatest success in terms of modified agricultural practices arising from scientific research in biological nitrogen fixation (BNF) has been the development of rhizobial inoculants (Giller \& Cadisch, 1995). Rhizobial inoculation has the capability for soil fertility improvement in cereal-based cropping systems in the Guinea savanna agro-ecology (Carsky et al., 1996) since the bacteria is able to fix about $300 \mathrm{~kg} \mathrm{ha}^{-1}$ atmospheric nitrogen leading to increased grain and biomass yields (Keyser \& Li, 1992). According to Okereke et al. (2004), lack of effective nodulation of soybean as a result of ineffective indigenous Rhizobial strains and also unavailability of suitable soybean varieties are among the causes of poor yields. There is therefore a wide gap between the crop's potential yield and harvested yields. The objective of this experiment was to evaluate the effects of rhizobium inoculants and growth stages on shoot dry matter for green manure and yield of soybean.

\section{Materials and Methods}

\subsection{Site Description}

The study was carried out in the 2012 farming season at the teaching and research farm field of the University for Development Studies, Nyankpala (latitude N 09 $24^{\prime} 15.9^{\prime \prime}$ and longitude W $01^{\circ} 00^{\prime} 12.1^{\prime \prime}$ ) in the Guinea Savanna agro-ecological zone of Ghana. The soil of the study area is an Alfisol under the United State Development Agency system of classification and a savanna Ochrosol under the Ghana System of classification. The soil is brown, moderately drained sandy loam, free from concretions, very shallow with a hard pan underneath the top few centimeters, developed from the Voltaian sandstone and classified as Nyankpala Series (Plinthic Acrisol). The study area has a unimodal rainfall pattern with an annual rainfall of $1034.4 \mathrm{~mm}$ normally distributed fairly from May to October. The study area has a mean monthly temperature of $22^{\circ} \mathrm{C}$ during the rainy season and a maximum of $34^{\circ} \mathrm{C}$ during dry season (Figure 1). The relative humidity in the area is at its maximum monthly value of 53\% during the dry season (Savannah Agricultural Research Institute, 2008).

\subsection{Experimental Design and Treatments}

The experiment was a $2 \times 4$ factorial laid out in a Randomized Complete Block design (RCBD) with eight treatments at four replications. The treatments were two inoculation regimes \{Inoculated (+In) and Uninoculated $(-I n)\}$ and four developmental growth stages (vegetative, flowering, full pod and physiological maturity). The summarised treatments were: R1+In (vegetative plus inoculated), R2+In (flowering plus inoculated), R3+In (full pod plus inoculated), R4+In (physiological maturity plus inoculated), R1-In (vegetative minus inoculated), R2-In (flowering minus inoculated), R3-In (full pod minus inoculated) and R4-In (physiological maturity minus inoculated). Plots were $2.5 \mathrm{~m}$ long and $2.5 \mathrm{~m}$ wide.

\subsection{Seed Acquisition and Characteristics of Soybean Cultivar (Jenguma)}

Seeds of an improved soybean variety, Jenguma developed and released by CSIR-Savanna Agricultural Research Institute, Nyankpala were used for the trial. It is an improved soybean variety with a very high shattering resistance and a maturity period of 115 days. Soybean cultivar (Jenguma) grows well under warm and moist climatic conditions with an optimum temperature of 26 to $32^{\circ} \mathrm{C}$. It grows on well-drained fertile loamy soils with a $\mathrm{pH}$ of 5.5 to 7.5 . It has a potential yield of $2.0 \mathrm{t} / \mathrm{ha}$ and is very rich in protein and oil with a ratio of $2: 1$. Jenguma has a protein content of $0.57 \%$ (dry weight basis) and fat/oil content of $0.39 \%$ (dry weight basis).

\subsection{Inoculation and Sowing}

Commercial Rhizobium inoculant, Legumefix (containing $1 \times 10^{9}$ cells/g) was used for the study. The Legumefix was imported from Legume Technology Limited, UK and kept at $4^{\circ} \mathrm{C}$ prior to inoculation of the seeds. The seeds were inoculated at the rate of $1 \mathrm{~kg}$ seed per $5 \mathrm{~g}$ of Legumefix. The soybean seeds were measured out in a plastic pail and moistened with ordinary tap water and then stirred uniformly with a wooden spatula. The inoculants was added to the moistened seed in the container and again stirred gently and uniformly until the seeds were fairly evenly coated. The seeds were then spread on a sheet of canvas material under a shade to air-dry for at least one hour to allow the inoculants to adequately adhere to the surface of the seeds. To avoid direct exposure of the coated seeds to sunlight, the seeds were sown immediately at two seeds per hill at $50 \mathrm{~cm}$ (inter-row) x $10 \mathrm{~cm}$ (interplant) and was immediately covered. The un-inoculated seeds were sown before the inoculated ones in order to avoid contamination of the former. 


\subsection{Management Practices}

The experimental field was ploughed and harrowed using a tractor and ridges constructed manually. Three manual weeding operations were carried out using the hand-hoe at two, five and nine weeks after sowing. The experiment was conducted under rainfed conditions. Mineral fertilizer (Triple Superphosphate) was applied uniformly at the rate of $30 \mathrm{~kg} \mathrm{P} / \mathrm{ha}$ at two weeks after sowing by burying the fertilizer material in trenches dug at $5 \mathrm{~cm}$ away from the hill. The plants did not suffer from any major pest and disease attack during their growth hence no spraying was done.

\subsection{Data Collected}

\subsubsection{Measurement of Crop Variables}

Data collected on crop establishment, plant height, leaf area, canopy spread, number of pods and pod weight per plant and total grain weight were averaged for the whole inoculated and uninoculated treatments. The data on number of nodules, weight of nodules and fresh and dry weights of shoot were taken for both inoculated and uninoculated plots as well as from developmental stages.

\subsubsection{Crop Establishment}

This parameter was taken by counting the emerged plants on the three innermost ridges of each plot at two weeks after sowing which was expressed in percentage as number of emerged plants divided by expected number of plants multiply by 100 .

\subsubsection{Plant Height}

Five plants were randomly selected from the three innermost ridges each from both the inoculated and un-inoculated plots and tagged. The heights of the five selected plants were measured from the base of each plant to the last terminal leaf of the plant at three, six and nine weeks after sowing using a measuring tape. The five readings from each plot were averaged and recorded.

\subsubsection{Canopy Spread}

The canopy spread of the five plants that were selectively tagged for height measurements was also monitored. The canopy spread was measured from the last leaf on one side of the plant to the last leaf on the other side of the same plant using a measuring tape. This measurement was done at the same times and intervals as plant heights were measured.

\subsubsection{Leaf Area}

This parameter was measured on the same plants whose heights and canopy spreads were measured and at the same periods after sowing. The length and breadth of the leaves from the five tagged plants were measured and their means calculated and recorded.

\subsubsection{Fresh Shoot and Dry Weights and Number and Dry Weights of Nodules}

These parameters were measured on five plants sampled from the three innermost ridges of each plot at the vegetative, flowering, full pod and physiological maturity stages. The plants were uprooted carefully by loosening the soil around them with a cutlass before pulling them out gently with the hand making sure to collect the few nodules that got detached from the roots in the process. The roots were then severed from the plants, washed carefully on a $2 \mathrm{~mm}$ sieve under a jet of tap water to remove any adhering soil and organic debris after which the nodules were detached from the roots and counted and the fresh shoots also weighed. The nodules and the shoot samples were then dried separately at $80^{\circ} \mathrm{C}$ in an oven for $48 \mathrm{~h}$ to constant weights and the nodule and shoot dry weights were recorded. The weight measurements were done using an electronic digital balance.

\subsubsection{Number and Weight of Pods}

The pods detached from the five plants sampled at the full pod and physiological maturity stages, respectively were counted and weighed and their means recorded.

\subsubsection{Grain Yield}

At full maturity when the pods were generally dried, all the remaining plants on the three innermost ridges (the net plot) were harvested by manually pulling them out of the ground and the pods detached from the plants, weighed, shelled and the grains separated from the husks. The grains were further dried on a concrete platform to a moisture content of $13 \%$ using a moisture meter and then weighed. 


\subsection{Data Analysis}

Data collected were subjected to analyses of variance (ANOVA) using Genstat (2008 Edition) and treatment means compared using the Least Significance Difference (LSD) at 5\% probability level.

\section{Results}

The amount of rainfall distribution in 2012 cropping season was high from June to September (Figure 1). The rains were well distributed throughout the growing season. However, the high amount of rainfall might have created leaching of nutrients beyond the reach of the plants.

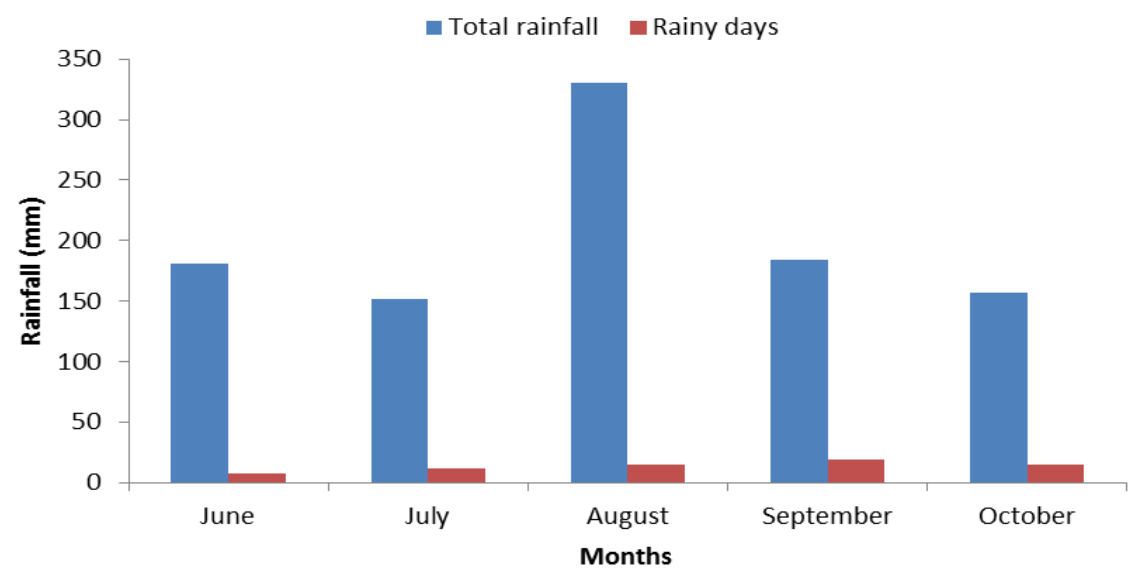

Figure 1. Total rainfall and number of rainy days from July to September, 2012

Gravimetric moisture content was $15 \%$ at the time of sowing but reduced to $13 \%$ between 2 WAP and 3 WAP because of failure of the rains. The moisture content however increased from 5 WAP to $12 \mathrm{WAP}$ and reduced again to $12 \%$ at 12 WAP (Figure 2).

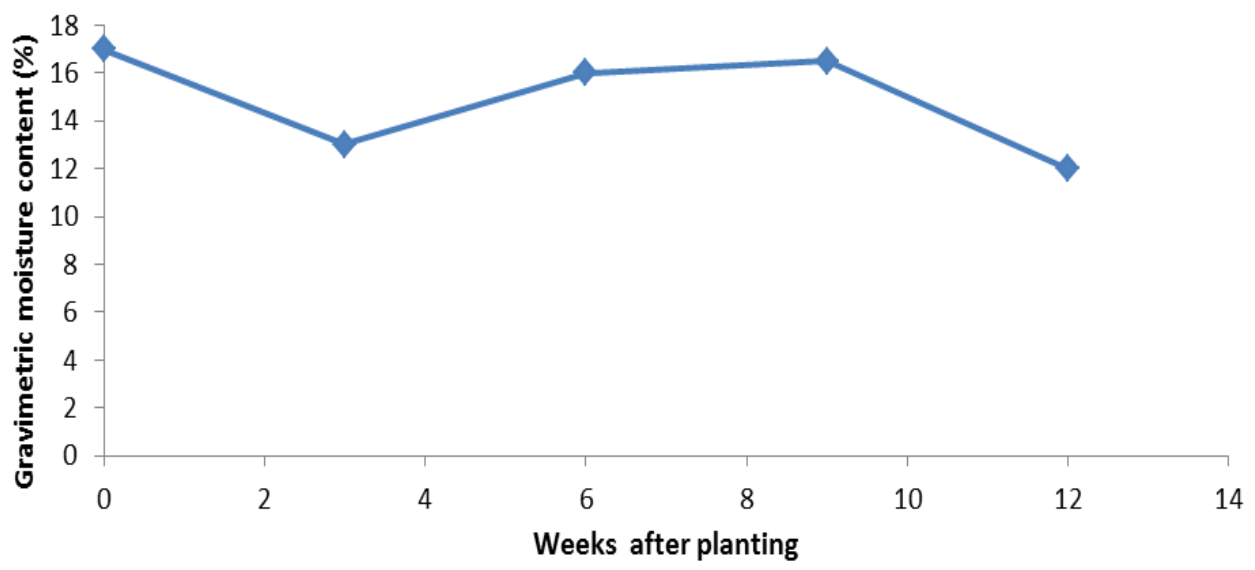

Figure 2. Gravimetric soil moisture content from July to September, 2012

\subsection{Growth Parameters}

\subsubsection{Crop Establishment}

Figure 3 shows the results of crop establishment which reveals that plots inoculated with Rhizobium recorded the highest percentage of crop establishment (52.5\%) though not significant at $\mathrm{P}>0.05$. 


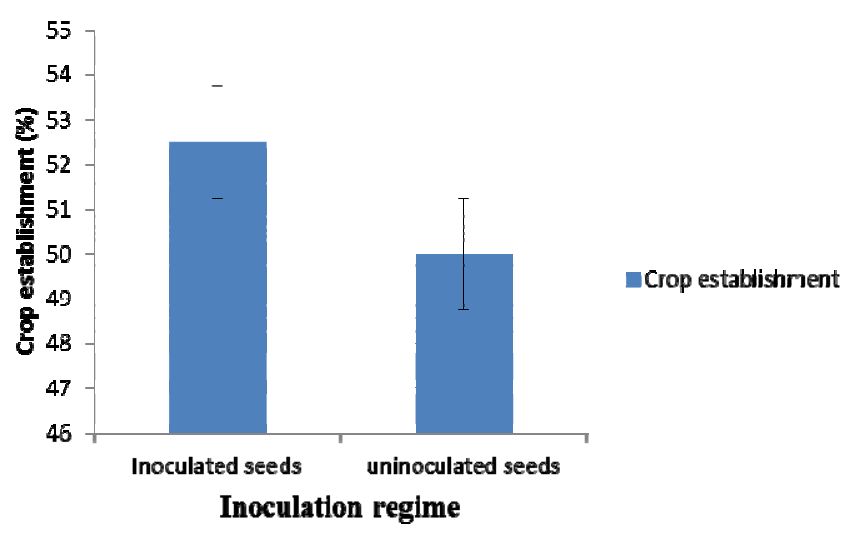

Figure 3. Effect of inoculation regime on crop establishment of soybean. Bars represent SEM

\subsubsection{Plant Height $(\mathrm{cm})$}

Inoculation with Rhizobium produced significantly $(\mathrm{P}<0.05)$ taller soybean plants throughout the sampling period with the greatest effect $(53.4 \mathrm{~cm})$ being experienced at 9 WAP compared to the heights $(48.9 \mathrm{~cm})$ of un-inoculated plants at the same stage (Figure 4).

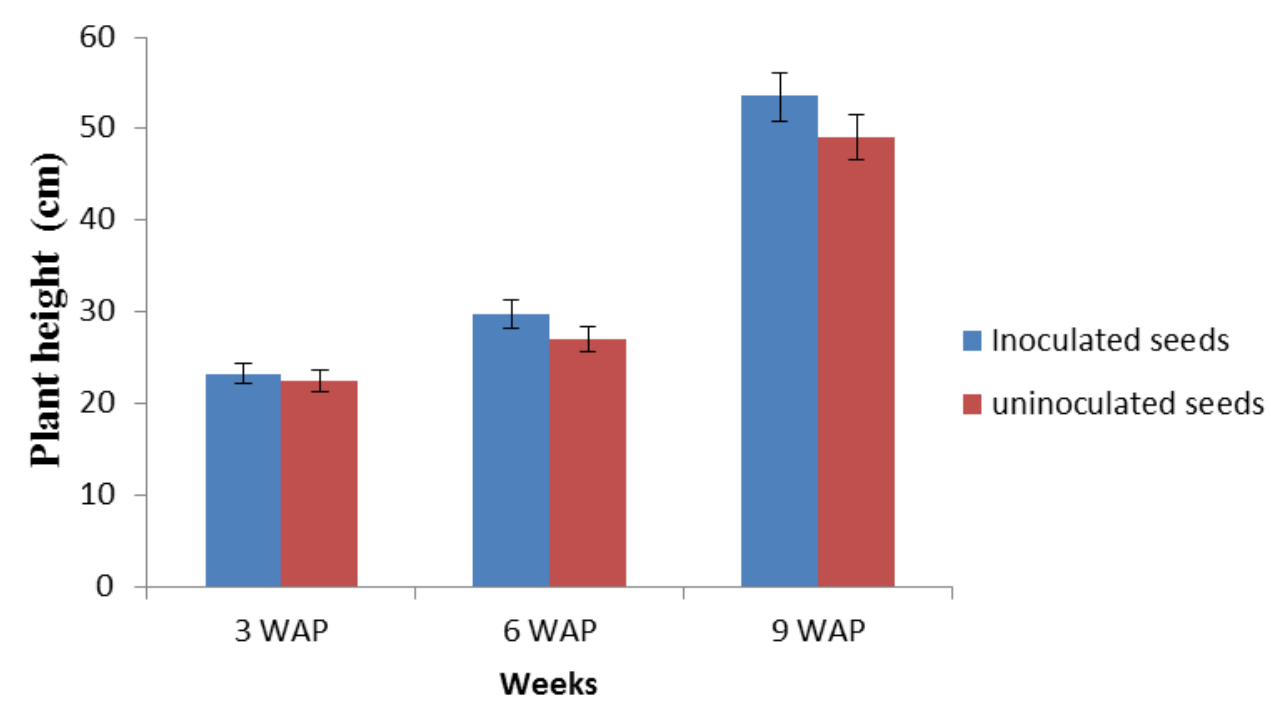

Figure 4. Effect of inoculation regime on plant height of soybean. Bars represent SEM

\subsubsection{Canopy Spread $\left(\mathrm{cm}^{2}\right)$}

Analysis of the results on canopy spread showed that treatment effects were not significantly different $(\mathrm{P}>0.05)$ at 6 WAP and 9 WAP (Figure 5). However, at 3 WAP inoculated plants had significantly greater $(\mathrm{P}<0.05)$ canopy spread of $25.6 \mathrm{~cm}$ compared to the mean canopy spread $(20.2 \mathrm{~cm})$ of un-inoculated plants. Irrespective of inoculation regime, plants consistently showed an increase in canopy spread at every higher growth stage. 


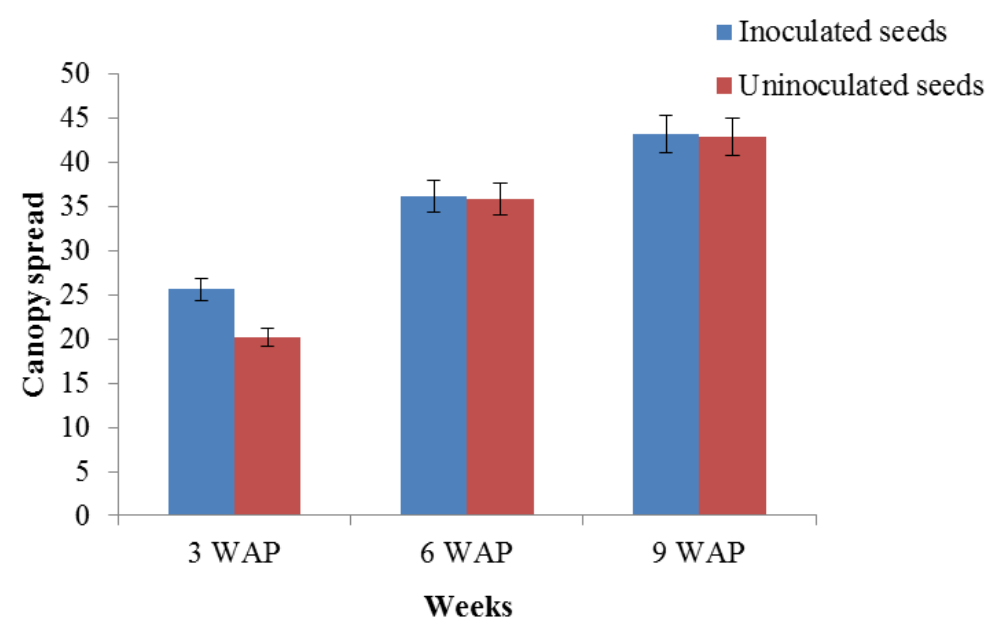

Figure 5. Effect of inoculation regime on canopy spread of soybean. Bars represent SEM

\subsubsection{Leaf Area $\left(\mathrm{cm}^{2}\right)$}

Result of Leaf area at 3, 6 and 9 weeks after planting is presented in Figure 6. Inoculation with Rhizobium had a significant effect on the leaf area of Jenguma only at 9 WAP though there were slight increases due to this treatment at the earlier growth stages sampled (Figure 6).

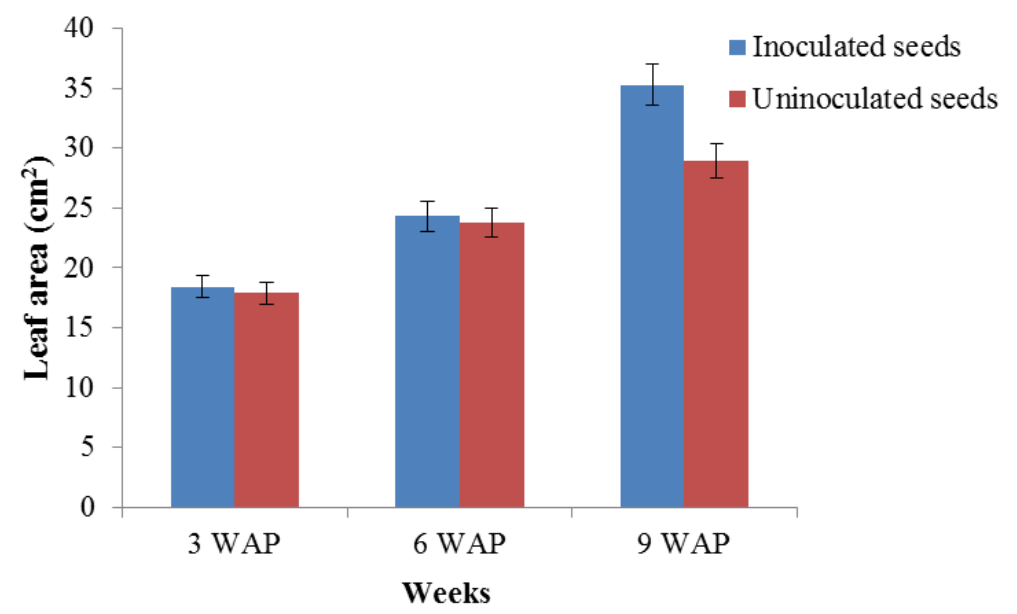

Figure 6. Effect of inoculation regime on soybean leaf area. Bars represent SEM

\subsection{Yield Components}

\subsubsection{Number and Weight of Nodules}

Nodulation of Jenguma was significantly $(\mathrm{P}<0.05)$ influenced by inoculation regime and growth stage (Table 1). Nodule formation and nodule biomass production were at their highest (109 nodules plant ${ }^{-1}$ and $1.3 \mathrm{~g} \mathrm{plant}^{-1}$, respectively) in inoculated plants at the full pod stage followed by flowering stage (74 nodules plant ${ }^{-1}$ and $0.9 \mathrm{~g}$ plant $^{-1}$, respectively) whereas these parameters were least at the physiological maturity stage $\left(9\right.$ nodules plant ${ }^{-1}$ and $0.2 \mathrm{~g} \mathrm{plant}^{-1}$, respectively). A similar trend was observed in the un-inoculated plants with un-inoculated plants sampled at the physiological maturity stage producing the smallest as well as the least number of nodules (Table 1). 
Table 1. Influence of inoculation regime and growth stages on nodule number and nodule weight $(\mathrm{g})$ of soybean

\begin{tabular}{lcc}
\hline Treatment & $\begin{array}{c}\text { Nodule number } \\
\text { Per plant }\end{array}$ & $\begin{array}{c}\text { Nodule weight } \\
\text { Per plant }\end{array}$ \\
\hline R1+In & 57.8 & 0.8 \\
R2+In & 73.8 & 0.9 \\
R3+In & 108.5 & 1.3 \\
R4+In & 9.0 & 0.15 \\
R1-In & 38.0 & 0.4 \\
R2-In & 43.8 & 0.5 \\
R3-In & 61.5 & 0.6 \\
R4-In & 3.5 & 0.05 \\
LSD (5\%) & 24.03 & 0.31 \\
CV (\%) & 14.5 & 23.1 \\
\hline
\end{tabular}

\subsubsection{Number and Weight of Pods}

There were significant differences $(\mathrm{P}<0.05)$ between inoculated and un-inoculated plants with regard to pod number and pod weight of Jenguma at harvest (Figure $7 \& 8$ ). The numbers of pods harvested from the inoculated and un-inoculated plants were 55 and 37 per plant, respectively with the corresponding weights of $91.1 \mathrm{~g}$ and 66.1 g per plant.

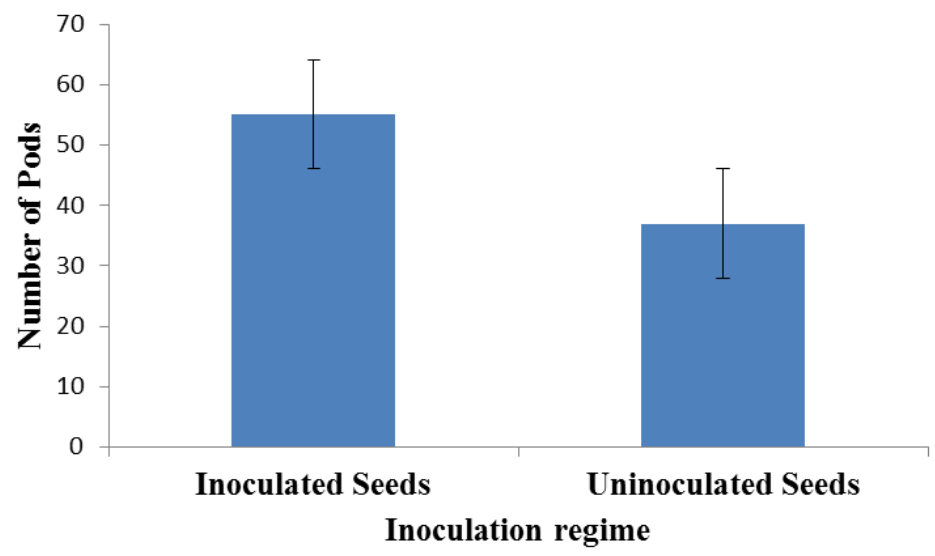

Figure 7. Effect of inoculation regime on number of pods of soybean. Bars represent SEM

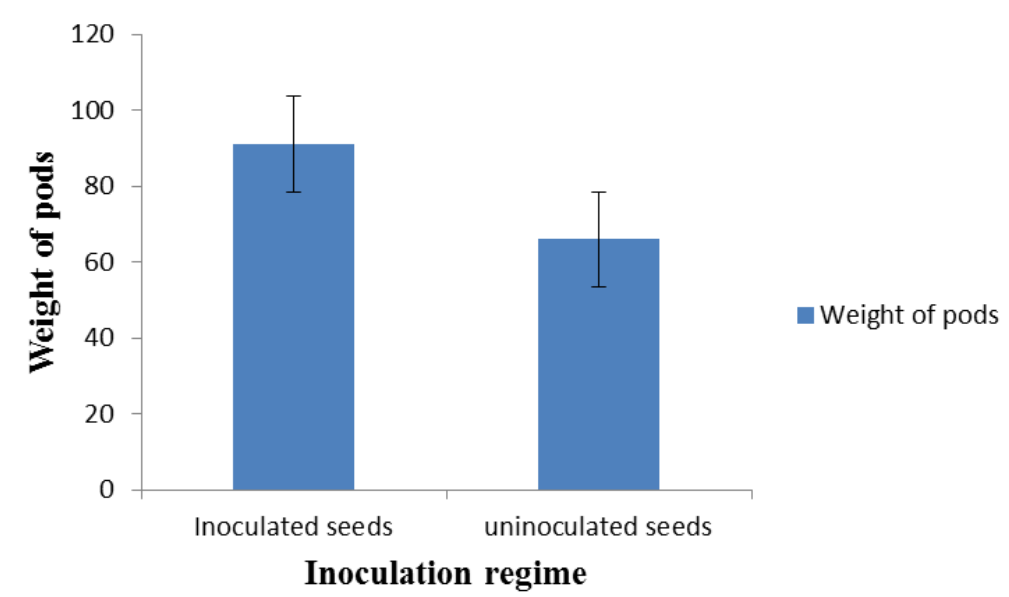

Figure 8. Effect of inoculation regime on weight of pods of soybean. Bars represent SEM 


\subsubsection{Fresh and Dry Shoot Weight of Soybean}

Within an inoculation regime no increases were observed in both the fresh and dry shoot weights at any of the growth stages (Table 2). However, inoculation with Rhizobium $(+\operatorname{In})$ produced significantly higher fresh shoot biomass at flowering and full pod stages compared to their un-inoculated counterparts at the same growth stages.

Table 2. Influence of inoculation regime and growth stages on fresh and dry shoot weight $(\mathrm{g})$ of soybean

\begin{tabular}{ccc}
\hline Treatment & $\begin{array}{c}\text { Fresh shoot weight (g) } \\
\text { Per plant }\end{array}$ & $\begin{array}{c}\text { Dry shoot weight (g) } \\
\text { Per plant }\end{array}$ \\
\hline R1+In & 62.8 & 20.57 \\
R2+In & 69.1 & 21.60 \\
R3+In & 74.2 & 23.57 \\
R4+In & 62.1 & 20.45 \\
R1-In & 45.7 & 15.50 \\
R2-In & 46.0 & 16.42 \\
R3-In & 50.5 & 16.65 \\
R4-In & 45.2 & 15.35 \\
LSD (5\%) & 18.0 & 11.94 \\
CV (\%) & 21.6 & 26.6 \\
\hline
\end{tabular}

\subsubsection{Total Grain Yield (kg/ha)}

Results of grain yield of soybean are presented in Figure 9. Inoculation of Jenguma with the commercial Rhizobium inoculants, Legumefix remarkably increased its grain yield by $21 \%$ from $1044 \mathrm{~kg} / \mathrm{ha}$ in the un-inoculated treatment to $1262 \mathrm{~kg} /$ ha (Figure 9).

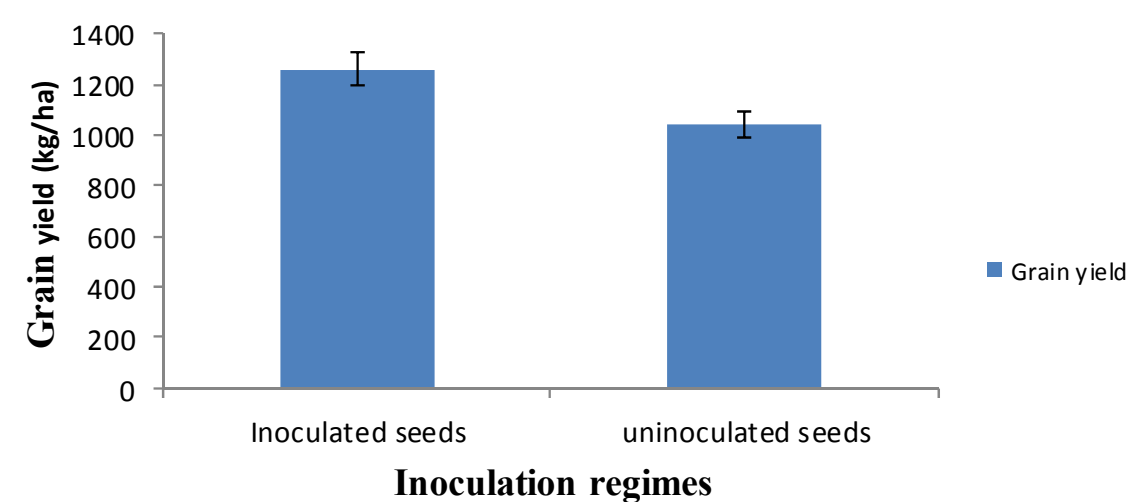

Figure 9. Effects of inoculation regime on total grain yield of soybean. Bars represent SEM

\subsection{Correlation Among Traits}

The estimated correlation among traits is presented in Table 3. Significant positive correlation was observed between grain yield and the traits plant stand, plant height, canopy spread, number of nodules, number of pods, weight of nodules and weight of pods. Shoot weight was negatively correlated with grain yield and plant height. The highest significant positive correlation was observed between number of nodules and weight of nodules. The lowest correlation was observed between plant stand and canopy spread. Weight of nodules was positively correlated with all the traits measured, whilst the number of nodules was also positively correlated with all the parameters except plant stand. 
Table 3. Correlation analysis of metric traits of soybeans evaluated under inoculation regimes and growth stages

\begin{tabular}{llllllllllllll}
\hline Traits & & & & & & & & & & \\
\hline 1. Canopy spread & 1 & & & & & & & & & \\
2. Plant stand & 0.11 & 1 & & & & & & & & \\
3. Leaf area & $0.69^{*}$ & -0.37 & 1 & & & & & & & \\
4. No of nodules & 0.33 & -0.06 & 0.41 & 1 & & & & & & \\
5. NO of pods & $0.62^{*}$ & -0.18 & $0.60^{*}$ & 0.47 & 1 & & & & & \\
6. Plant height & $0.85^{*}$ & -0.27 & $0.68^{*}$ & 0.37 & $0.56^{*}$ & 1 & & & & \\
7. Weight of Nodules & 0.22 & 0.14 & 0.18 & $0.90^{*}$ & 0.45 & 0.26 & 1 & & & \\
8. Weight of pods & 0.3 & -0.29 & 0.34 & 0.05 & $0.67^{*}$ & 0.34 & 0.04 & 1 & & \\
9. Weight of shoot & 0.07 & 0.27 & 0.05 & 0.17 & 0.08 & -0.19 & 0.15 & 0.06 & 1 & \\
10. Grain yield & $0.77^{*}$ & 0.03 & $0.53^{*}$ & 0.44 & $0.50^{*}$ & $0.78^{*}$ & 0.44 & 0.18 & -0.04 & 1 \\
& 1 & 2 & 3 & 4 & 5 & 6 & 7 & 8 & 9 & 10 \\
\hline
\end{tabular}

* Correlation is significant at $\mathrm{P}<0.05 * *$ Correlation is significant at $\mathrm{P}<0.01$.

\section{Discussion}

Crop establishment indicates the germination ability and seedling survival of the treatments. Inoculated plants were more established than those in un-inoculated plots and this could have been due to a greater vigour exhibited by such plants as a result of their better growth due to Rhizobium inoculations other than the genetic and environmental factors such as amount of soil moisture and temperature which are believed to be responsible for differences in plant stands (Ahmad \& Mohammad, 1997). The increased in plant establishment of inoculated seeds resulting from enhanced plant vigour could be a result of improved soil productivity due to bacterial activity and available nutrients (Gunarto, 2000). Plant height is influenced by both genetic and environmental factors. Plants compete with other plants and weeds for light and other growth resources. To out-compete weeds, plants need to outgrow and shade the weeds rapidly. Plant height therefore is an important plant genetic attribute. There were significant influences among the treatment for plant height. This is in agreement with Hernandez and Cuevas (2003) who stated that inoculation increased plant height. The rate at which plant canopy forms and closes is of agronomic importance. Closed plant canopy intercepts more solar radiation, reduces loss of nutrients through soil erosion, smothers young weeds and prevents weed seeds from germinating. Plants have a potential to achieve a certain height and canopy width but the actual size of the canopy usually depend on factors such as variety, plant spacing and availability of nutrients. Stafanescu and Palanciuc (2000) observed that the greater canopy in inoculated plots could be linked to increased nitrogen fixation and improved soybean nutrition which caused greater vegetative growth. Wafaa et al. (2002) also concluded that Rhizobium japonicum inoculums enabled soybean to display a better growth. The increased canopy width observed in inoculated plants in this study could therefore be attributed to the enhanced shoot growth of such plants. This result agrees with the findings of Mallik et al. (2006) who stated that inoculation promotes growth factors such as production of larger leaves.

Giller and Wilson (1991) observed that the ability of legumes to nodulate and fix nitrogen is a genetic factor affected by environmental conditions and that nodulation and nitrogen fixation require large amounts of the plants dry matter meaning that nodulation will be at the expense of dry matter production. However, in this study, both nodulation (nodule dry weight and nodule number) and shoot dry matter production reached a peak at the pod filling stage suggesting that dry matter production and partitioning were not sacrificed for nodulation. It can therefore be fairly concluded that differences in shoot dry matter were due to the effective nodulation of the Rhizobium inoculants. This confirms the study conducted by Stefanescu and Palanciuc (2000) which revealed that shoot dry matter of the inoculated treatments were significantly greater than that of the control as a result of increases in nodulation. However, whereas Stefanescu and Palanciuc (2000) and Lawn (1989) suggested that it was appropriate to harvest or plough soybean into the soil at flowering as green manure, our results revealed that full pod stage would be a more appropriate stage to do so. The correspondence of number of nodules with their weight in this work, especially in inoculated treatments, also confirms the findings of Lawson and Quainoo (2008) that nodule dry biomass followed the same pattern as the nodule count. Revellin et al. (2000) also observed that higher numbers of nodules per plant resulted in higher plant biomass. The observation in this study of a significant high level of nodulation at full pod stage (a possible indication of increased $\mathrm{N}_{2}$ fixation) contradicts the finding of Zapata et al. (1987) that maximum $\mathrm{N}_{2}$ fixation occurs between the flowering and early pod stages 
of soybean development. If nodulation is a direct index of $\mathrm{N}_{2}$ Fixation activity, then the drastic drop in nodulation between the full pod stage and the physiological maturity stage could lead to a shortage of $\mathrm{N}$ during seed-filling in high-yielding environments. This assertion is confirmed by Pedersen (2009) who observed that the demand for nitrogen is extremely high during seed formation immediately after flowering. The highly significant $49 \%$ increase in mean number of pods per plant and 38\% increase in mean pod weight per plant due to Rhizobium inoculation, which remarkably enhanced nodulation at full pod stage, resulted in a $21 \%$ grain yield. Okereke et al. (2004) reported that lack of effective nodulation and unavailability of suitable varieties are among the causes of poor yield in soybean. It could therefore be inferred that even though the remarkable drop in nodulation at physiological maturity stage could lead to a shortage of $\mathrm{N}$ during seed filling (seed $\mathrm{N}$ was not measured in this work). According to Pedersen (2009), the accelerated nodulation activity at full pod stage was sufficient to maintain a high pod formation and increased grain yield at maturity. This is also in line with the study conducted by Glover and Lindermann (2003), Conley and Christmas (2006) and Dashti et al. (1995) which stated that inoculated seeds produced higher grain yield than the control due to increased nodulation. Keyser and Li (1992) concluded from their investigation that inoculation of soybean is a significant agency for the manipulation of rhizobium for improving crop productivity and soil fertility.

The observation of positive correlation between grain yield and traits like plant height, plant canopy spread and number of pods implies that indirect selection of suitable varieties via these traits could result in grain yield improvement. The results suggested that the rate of grain yield kept pace with the rate of crop growth and yield components. It can therefore be inferred that grain yield is largely dependent on the effect of the growth traits such as plant height, plant canopy spread and some yield components. Hence, inoculation regimes and sampling growth stages that promote high growth traits and yield components will have positive influence on grain yield (Carpenter \& Board, 1997b). The significant correlation between the yield components (nodule number, nodule weight, pods number, pod weight) and grain yield indicates that the selection of these components of yield will generally be effective for high grain yield. Hence, inoculation regimes and sampling growth stages that promote high growth traits and yield components would have positive influence on grain production of soybean.

\section{Conclusion and Recommendation}

Soybean seeds inoculated with commercial Rhizobium inoculants (Legumefix) established better, grew more vegetatively, produced higher shoot biomass at full pod stage, nodulated more vigorously at full pod stage and produced more pods, which resulted in increased grain yield. The study therefore recommends that for increased yield, soybean seeds should be inoculated before planting. Also, for higher nodule number, nodule weight and shoot biomass for green manuring, soybeans plants should be harvested at full pod stage.

\section{Acknowledgments}

The authors wish to thank the University for Development Studies, Nyankpala for releasing their teaching and research field for the conduct of this study. We would also like to express our appreciation to the CSIR-Savanna Agricultural Research Institute, Tamale for allowing us to use their Soil Microbiology laboratory where almost all the handling of samples and measurements were done. Finally, we sincerely thank the N2Africa Project for supplying us with the commercial inoculants, Legumefix.

\section{References}

Ahmad, N., \& Rahim, M. (2007). Evaluation of promising groundnut, Arachis hypogaea L. varieties for yield and other characters. J. Agric. Res, 45(3), 185-189.

Board, J. E., \& Hall, W. (1983). Premature flowering in soybean yield reductions at non optimal planting dates as influenced by temperature and photoperiod. Agron. J., 76, 700-704. http://dx.doi.org/10.2134/a gronj1984.0002 $1962007600040043 x$

Carpenter, A. C., \& Board, J. E. (1997b). Growth dynamic factors controlling soybean yield Stability across plant populations. Crop Sci., 37, 1520-1526. http://dx.doi.org/10.2135/cropsci1997.0011183X003700050018x

Carskey, R. J., Abaidoo, R., Dashiell, K., \& Sanginga, N. (1996). Effect of soybean on subsequent maize grain yield in Guinea Savanna of West Africa. African Crop Science J., 5(1), 31.

Conley, S., \& Christmas, E. (2006). Utilizing inoculants in a corn-soybean rotation. Purdue Ext. Bull. SPS-100-W. Purdue Univ., West Lafayette, IN.

Dashti, N., Zhang, F., Hynes, R., \& Smith, D. L. (1995). Application of plant growth promoting rhizobacteria to soybean (Glycine max (L.) Merr.) increases protein and dry matter yield under shortseason conditions. Plant Soil, 188, 33-41. http://dx.doi.org/10.1023/A:1004295827311 
Giller, K. E., \& Cadisch, G. (1995). Future benefits from biological Nitrogen fixation: An ecological approach to agriculture. Plant and Soil, 174, 255-277. http://dx.doi.org/10.1007/BF00032251

Glover, C. R., \& Lindemann, W. C. (2003). Nitrogen fixation by legumes. New Mexico State Univ. Coop. Ext. Serv. Guide A-129. New Mexico State Univ., Las Cruces.

Gunarto, L. (2000). Rhizosphere microbes: their roles and potential. J. Penelitian Dan Pengembangan Pertanian, 19, 39-48.

Hernández, M., \& Cuevas, F. (2003). The effect of inoculating with arbuscular mycorrhiza and Bradyrhizobium strains on soybean (Glycine max (L.) Merrill) crop development. Cultivos Tropicales, 24(2), 19-21.

International Institute of Tropical Agriculture (IITA). (1990). Annual Report of the International Institute of Tropical Agriculture, Ibadan Nigeria (pp. 45-47).

Keyser, H. H., \& Li, F. (1992). Potential for increasing biological nitrogen fixation in soybean. Plant and Soil, 141, 119-135. http://dx.doi.org/10.1007/BF00011313

Lawn, R. J. (1989). Agronomic and physiological constraints to the productivity of tropical grain legumes and prospects for improvement. Exp. Agric., 25, 509-528. http://dx.doi.org/10.1017/S0014479700015143

Lawson, I. Y. D., \& Quainoo, A. (2008). Response of soybean to organic matter application and inoculation with Brady rhizobium japonicum in the Guinea savanna of Ghana. J. Ghana Sci. Ass., 4(1), 53-57.

Malik, M. F. A., Qureshi, A. S., Ashraf, M., \& Ghafoor, A. (2006). Genetic variability of the main yield related characters in soybean. Intl. J. Agric. and Biol., 8(6), 815-819.

Mamman, I. (1990). Soybean in Nigeria Agriculture. Paper delivered by the Honourable Minister of Agriculture and Natural Resources 3rd Annual conference of Nigeria Soybean Association, Badeggi (March 1990, pp. 26-29).

Miller, D. R., Rosenberg, N. J., \& Bagly, W. T. (1997). Soybean water use in the shelter of a saltfence windbreak. Agric. Meteorol., 11, 405-418. http://dx.doi.org/10.1016/0002-1571(73)90086-1

Okereke, G. U., Onochie, C., Onunkwo, A., \& Onyeagba, E. (2004). Effectiveness of foreign Brady rhizobia strains in enhancing nodulation, dry matter and seed yield of soybean (Glycine max L.) cultivars in Nigeria. Biol. Fertil. Soils, 33, 3-9. http://dx.doi.org/10.1007/s003740000264

Pedersen, P. (2009). Managing soybean for high yield. Iowa State University, Department of Agronomy Retrieved July 12, 2011, from http://www.extension.agron.iastate.edu/soybean/documents/HighYield.pdf

Revellin, C., Meunier, G., Giraud, J. J., Sommer, G., Wadoux, P., \& Catroux, G. (2000). Changes in the physiological and agricultural characteristics of peat-based Brady rhizobium japonicum inoculants after long-term storage. Appl. Microbiol. Biotechnol, 54, 206-211. http://dx.doi.org/10.1007/s002530000373

Savannah Agricultural Research Institute. (2008). Annual report for the year 2008. Savannah Agricultural Research Institute, P. O. Box 52, Tamale, Ghana.

Shu-Jie, M., Yun-Fa, Q., Xiao-Zeng, H., \& An, M. (2007). Nodule formation and development in soybeans (Glycine mux L.) in response to phosphorus supply in solution culture. Pedosphere, 17, 36-43. http://dx.doi.org/10.1016/S1002-0160(07)60005-8

Stefanescu, M., \& Palanciuc, V. (2000). Efficiency of bacterial inoculation and mineral nitrogen and phosphorus fertilization in rainfed soybean. Roma. Agric. Res., 13-14, 75-83.

United States Department of Agriculture National Agriculture Statistics Service (USDANASS). (2011). Retrieved from https: //www.ers.usda.gov/statefacts/us.htm

Wafaa, W. M., El-Marakby, A. M., Abdel-Halim, A. A., \& Afaf, M. T. (2002). Evaluation of performance and stability of some soybean genotypes under different environments. Annuals of Agricultural Science (Cairo), 47(2), 621-640.

Zapata, F., Danso, S. K. A., Hardarson, G., \& Fried, M. (1987): Time course of nitrogen fixation in field-grown soybean using nitrogen-15 methodology. Agron. J., 79, 172-176. http://dx.doi.org/10.2134/agronj198 $7.00021962007900010035 x$

\section{Copyrights}

Copyright for this article is retained by the author(s), with first publication rights granted to the journal.

This is an open-access article distributed under the terms and conditions of the Creative Commons Attribution license (http://creativecommons.org/licenses/by/3.0/). 